\title{
Identification of quantitative trait loci for growth and carcass composition in cattle ${ }^{1}$
}

\author{
E. Casas, J. W. Keele, S. D. Shackelford, M. Koohmaraie and R. T. Stone \\ USDA-ARS, US Meat Animal Research Center, Clay Center, NE, USA
}

Summary

\section{Introduction}

Studies aimed at detecting quantitative trait loci (QTL) for growth and carcass composition of cattle have been successfully conducted (Keele et al. 1999; Stone et al. 1999; Casas et al. 2000; Casas et al. 2001; MacNeil \& Grosz 2002;

Address for correspondence

E. Casas, USDA-ARS, US Meat Animal Research Center, Clay center, NE 68933-0166, USA.

E-mail:casas@email.marc.usda.gov

${ }^{1}$ Mention of a trade name, proprietary product, or specified equipment does not constitute a guarantee or warranty by the USDA and does not imply approval to the exclusion of other products that may be suitable. This article is the material of the US Government and can be produced by the public at will.

Accepted for publication 8 October 2003
Kim et al. 2003). These QTL will potentially benefit genetic selection programmes, especially carcass composition and meat quality traits, which are difficult and expensive to measure.

Part of our strategy for detecting QTL in two large half-sib families obtained from crossbred sires, from Bos taurus and Bos indicus, has been to genotype a subset of the families selected from the extremes for economically important traits. We have previously reported QTL defined by selective genotyping of a family obtained from a Brahman $\times$ Hereford sire (Stone et al. 1999). The objective of the present study was to identify chromosomal regions containing QTL influencing growth and carcass composition traits on selected progeny from a crossbred Brahman $\times$ Angus sire. This will provide a basis for targeting genomic regions to verify QTL in the remaining offspring of these sires and in additional populations. 


\section{Materials and methods}

\section{Animals}

A half-sib family was developed using a crossbred Brahman $\times$ Angus sire. The bull was previously used in the USDA reference population to generate a cattle linkage map (Kappes et al. 1997). For this study, the sire was mated to Hereford, Angus, MARC III (1/4 Hereford, 1/4 Angus, $1 / 4$ Red Poll, and 1/4 Pinzgauer), and $F_{1}$ cows from the Germplasm Evaluation Project Cycle IV to produce 259 offspring in 1995, and mated to MARC III cows in 1996 to produce 361 offspring ( 620 offspring total). Breeds of sires for the $\mathrm{F}_{1}$ cows were Hereford, Angus, Shorthorn, Charolais, Gelbvieh, Pinzgauer, Galloway, Longhorn, Nellore, Piedmontese, or Salers. Breeds of dams for the $\mathrm{F}_{1}$ cows were Hereford or Angus. Calves were weaned at an average of 205 days and raised from weaning to slaughter on a corn-corn silage diet. Slaughter data were obtained at a commercial packing plant and the wholesale rib was obtained from the right side of each carcass for dissection (Shackelford et al. 1995). The average age at slaughter was 467 days.

\section{Traits analysed}

Offspring were evaluated for birth weight, carcass composition and meat quality traits. Carcass traits included hot carcass weight $(\mathrm{kg})$, marbling score $\left(400=\right.$ slight $^{00}$ and $500=$ small $^{00}$ ), USDA yield grade, estimated kidney, pelvic and heart fat $(\%)$. Carcass traits predicted from the rib dissection were retail product yield (\%) and fat yield (\%) (Shackelford et al. 1995). Mean values and SEs for the traits are given in Table 1.

\section{Genomic screen}

The development of the bovine genetic map at the US Meat Animal Research Center (Kappes et al. 1997; http://

Table 1 Mean SE and range for birth weight, hot carcass weight, marbling score, USDA yield grade, estimated kidney, heart and pelvic fat, fat yield, and retail product yield.

\begin{tabular}{lc}
\hline Trait & Mean \pm SE \\
\hline BWT (kg) & $40.7 \pm 0.4$ \\
HCW (kg) & $297 \pm 2$ \\
MAR $^{1}$ & $509 \pm 5$ \\
YG & $2.97 \pm 0.05$ \\
KPH (\%) & $3.02 \pm 0.04$ \\
FATYD (\%) & $23.6 \pm 0.3$ \\
RPYD (\%) & $62.8 \pm 0.3$ \\
\hline
\end{tabular}

BWT, birth weight; HCW, hot carcass weight; MAR, marbling; YG, USDA yield grade; KPH, estimated kidney, heart and pelvic fat; FATYD, fat yield; RPYD, retail product yield.

${ }^{1}$ MAR: $400=$ slight $^{00}$ and $500=$ small $^{00}$. www.marc.usda.gov) has resulted in the isolation of genetic markers across the genome. For this study, the primary screening was conducted using 219 microsatellite markers scanning the genome approximately every 10-15 centimorgan (cM). Informative markers in the sire were chosen based on their location and ease of scoring. Amplification reactions for each marker were done with purified DNA extracted from blood with a saturated salt procedure (Miller et al. 1988). Amplification conditions have been described elsewhere (Kappes et al. 1997).

Genotyping of extreme phenotypes, or selective genotyping, reduces the cost without losing substantial power for QTL detection (Lander \& Botstein 1989). The genomic screening was done by genotyping individuals with either the highest retail product yield and lowest fat yield or the lowest retail product yield and the highest fat yield. Individuals were selected based on the residuals from a model that included the fixed effects of year of birth (1995 or 1996), sex (steers or heifers), dam line and days on feed as a covariate. A total of 176 animals were used in this procedure, 88 from each selected group, which was $28 \%$ of the total offspring.

\section{Statistical analysis}

An F-statistic profile was generated at 1-cM intervals for each chromosome. Data were analysed using the approach suggested by Haley et al. (1994), with a model that included year of birth (1995 or 1996), sex (steers or heifers), dam line, days on feed as a covariate and the conditional probability of inheriting the Brahman allele from the sire at each $\mathrm{cM}$ of the chromosome as a covariate calculated with a FORTRAN program. The analysis for each chromosome was generated using the GLM procedure from SAS (SAS Institute Inc., Cart, NC). The LOD drop-off method was used to calculate support interval for each putative QTL (Ott 1992).

The experiment-wise threshold value was calculated according to Lander and Kruglyak (1995). An F-statistic was considered suggestive of linkage if it exceeded a value of $F=10.2$ (one expected number of false positive per genomic scan; ENFP = 1), and significant if it exceeded a threshold of $F=17.3$ (one false positive per 20 genomic scans; ENFP $=0.05)$. These results correspond to a nominal $P$-value of $P=0.002$ and $P=0.00005$, respectively.

\section{Results and discussion}

Quantitative trait loci were detected on eight chromosomes. One significant QTL (ENFP < 0.05) was identified for marbling score on chromosome 2. Fifteen suggestive QTL $($ ENFP $<1)$ were detected for seven other traits on chromosomes 1, 3, 16, 17, 20, 21, and 26.

A significant QTL (ENFP $=0.02$ ) for marbling score was apparent on chromosome 2 (Fig. 1). The support interval suggests that the QTL resides between cM 45 and 70, with a 


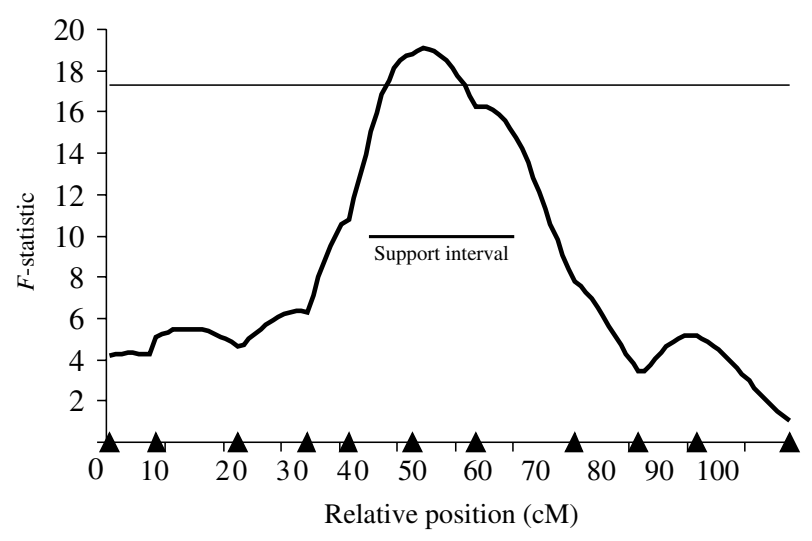

Figure 1 F-statistic profile and support interval for marbling score on bovine chromosome 2 . The upper horizontal line represents the significant threshold $(F=17.3)$. Triangles on the $x$-axis indicate the relative position of markers BMC9007, ILSTS026, TEXAN-2, URB042, BMS803, RM356, BMS353, TGLA226, BMS829, BMS2519 and IDVGA-2. maximum $F$-statistic at $54 \mathrm{cM}$. Animals inheriting the Angus allele had more marbling than animals inheriting the Brahman allele.

A QTL for marbling score was previously detected on chromosome 2. Stone et al. (1999) showed evidence suggesting the presence of a QTL for marbling score between cM 25 and 45 from the beginning of the linkage map of this chromosome. Stone et al. (1999) used 185 offspring from a total of 547 offspring selected on Warner-Bratzler shear force and on retail product yield, from a crossbred Brahman $\times$ Hereford sire. When the entire family $(n=547)$ was genotyped in this region of chromosome 2, the QTL for marbling score dropped below suggestive level (E. Casas, unpublished data) but still the statistical support was nominal $(P<0.01)$. The maximum $F$-statistic was at $35 \mathrm{cM}$ from the beginning of the linkage group, with a support interval spanning from cM 13 to 68. This support interval includes the interval detected in the present study. Lander and Kruglyak (1995) indicate that a QTL can be

Table 2 Relative position, support interval and allelic effects of putative QTL detected with a suggestive threshold.

\begin{tabular}{|c|c|c|c|c|c|c|c|c|}
\hline \multirow{2}{*}{$\begin{array}{l}\text { Chromosome } \\
\text { and trait }{ }^{1}\end{array}$} & \multirow{2}{*}{$\begin{array}{l}\text { Relative position } \\
(\mathrm{cM})^{2}\end{array}$} & \multicolumn{2}{|c|}{$\begin{array}{l}\text { Support } \\
\text { interval }(\mathrm{cM})^{2}\end{array}$} & \multirow[b]{2}{*}{ Effect $(B-A)^{3}$} & \multirow[b]{2}{*}{$F^{4}$} & \multirow[b]{2}{*}{$P^{5}$} & \multirow[b]{2}{*}{$P^{6}$} & \multirow[b]{2}{*}{ Bracketing markers ${ }^{7}$} \\
\hline & & Lower & Upper & & & & & \\
\hline \multicolumn{9}{|l|}{1} \\
\hline RPYD & 53 & 37 & 72 & + & 11.9 & 0.0007 & 0.49 & BMS948-ILSTSO83 \\
\hline FATYD & 50 & 38 & 74 & - & 12.5 & 0.0005 & 0.38 & BMS948-ILSTSO83 \\
\hline YG & 63 & 41 & 77 & - & 11.8 & 0.0007 & 0.51 & BMS948-ILSTSO83 \\
\hline \multicolumn{9}{|l|}{3} \\
\hline RPYD & 70 & 55 & 83 & + & 11.3 & 0.0009 & 0.64 & BMS1636-ILSTSO64 \\
\hline MAR & 56 & 9 & 74 & - & 10.5 & 0.001 & 0.89 & BM4129-BMS1636 \\
\hline $\mathrm{KPH}$ & 77 & 69 & 85 & - & 12.1 & 0.0006 & 0.46 & BMS1636-ILSTSO64-HUJI177 \\
\hline \multicolumn{9}{|l|}{16} \\
\hline MAR & 44 & 25 & 55 & + & 10.4 & 0.001 & 0.93 & HUJI614-IDVGA68 \\
\hline $\mathrm{KPH}$ & 62 & 39 & 73 & + & 14.0 & 0.0002 & 0.20 & BMS1207-IDVGA69 \\
\hline $\mathrm{HCW}$ & 49 & 32 & 57 & + & 13.8 & 0.0002 & 0.22 & IDVGA68-BMS1207 \\
\hline \multicolumn{9}{|l|}{17} \\
\hline FATYD & 35 & 0 & 63 & + & 10.9 & 0.001 & 0.75 & FCB48-BM305 \\
\hline \multicolumn{9}{|l|}{20} \\
\hline BWT & 12 & 0 & 24 & - & 11.6 & 0.0008 & 0.56 & HEL12-BMS1282 \\
\hline \multicolumn{9}{|l|}{21} \\
\hline BWT & 56 & 50 & 63 & + & 15.3 & 0.0001 & 0.12 & BMS2815-TGLA337-TGLA122 \\
\hline \multicolumn{9}{|r|}{ 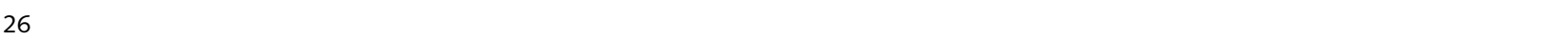 } \\
\hline RPYD & 26 & 15 & 41 & - & 11.6 & 0.0008 & 0.56 & BMS651-BLIO40-BM4505 \\
\hline FATYD & 26 & 16 & 38 & + & 11.1 & 0.001 & 0.69 & BMS651-BLIO4O-BM4505 \\
\hline YG & 26 & 21 & 36 & + & 16.7 & 0.00006 & 0.06 & BMS651-BLIO4O-BM4505 \\
\hline
\end{tabular}

BWT, birth weight; HCW, hot carcass weight; MAR, marbling; YG, USDA yield grade; KPH, estimated kidney, heart and pelvic fat; FATYD, fat yield; RPYD, retail product yield.

${ }^{1}$ MAR: $400=$ slight $^{00}$ and $500=$ small $^{00}$.

${ }^{2} \mathrm{CM}=$ relative position in $\mathrm{CM}$ from the beginning of the linkage map (Kappes et al. 1997).

${ }^{3} \mathrm{~B}$, Brahman; A, Angus (+, Brahman had a greater effect than Angus; -, Angus had a greater effect than Brahman).

${ }^{4}$ Maximum $F$-statistic in the interval.

${ }^{5}$ Probability of false positive for a single test.

${ }^{6}$ Expected number of false positive per scan (Lander \& Kruglyak 1995).

${ }^{7}$ Markers bracket the position of the maximum $F$-statistic. When three markers are shown, the middle marker is $<1 \mathrm{cM}$ from the maximum $F$-statistic. 
considered validated when there is significant evidence for its presence in a study, and at least a nominal significance of $P=0.01$ in other independent study. Therefore, the marbling score QTL on BTA2 is now validated. MacNeil and Grosz (2002) detected a QTL for marbling score on chromosome 2 using a double backcross derived from Line 1 Hereford and a Composite Gene Combination line. The maximum $F$-statistic was located at $120 \mathrm{cM}$ from the beginning of the linkage group. It is possible that two QTL for marbling score are segregating on this chromosome.

Seven chromosomes exhibited evidence for the presence of putative QTL (Table 2). Chromosomes 1, 3, 16 and 26, contain QTL for more than one trait.

Evidence suggesting the existence of a QTL associated with retail product yield and marbling score was identified in the middle of chromosome 3. A previous study (Casas et al. 2001) detected a similar QTL for both traits on this chromosome. The support interval for retail product yield in the present study includes the maximum $F$-statistic from the study by Casas et al. (2001). It is likely that the same QTL for these traits are segregating in both families. In the present study, animals inheriting the Angus allele from the sire had more marbling and less retail product yield when compared with animals inheriting the Brahman allele. Casas et al. (2001) indicated that animals inheriting the Belgian Blue allele had more marbling and less retail product yield than animals inheriting the MARC II allele. The allele from the dam could have been inherited from any of the four breeds that make the composite (Hereford, Angus, Red Poll or Pinzgauer). This result highlights the importance of characterizing allelic variation of QTL in several breeds and breed crosses to enable effective marker-assisted selection.

There is evidence suggesting the presence of a QTL for hot carcass weight on chromosome 16 . The most likely location of the QTL is between cM 32 and 57 from the beginning of the linkage group. MacNeil and Grosz (2002) detected a QTL for carcass weight on this chromosome. They indicated that the maximum $F$-statistic was at $1 \mathrm{cM}$ centromeric from marker BM9034. When comparing distances between the map provided by MacNeil and Grosz (2002) with the bovine linkage map (Kappes et al. 1997; http://www.marc.usda.gov), the former map is expanded. The position of BM9034 is at $37.5 \mathrm{cM}$ in our map of chromosome 16. This indicates that the most likely position of the QTL for hot carcass weight described by MacNeil and Grosz (2002) is between cM 35 and 37 of the linkage group. Thus, the position would be included in the support interval from the present study and suggest that the same gene, or group of genes, influences carcass weight in both the studies.

Chromosome 21 harbors QTL for birth weight. Davis et al. (1998) and Casas et al. (2003) detected a QTL for birth weight at the centromeric region of this chromosome but the QTL of the present study is telomeric of that region. Kim et al. (2003), using reciprocal backcrosses and F2 families from a cross between Angus and Brahman detected a QTL for birth weight in the same region where the QTL for birth weight was detected in the present study. Two QTL for the same trait reside on the same chromosome. However, to ascertain the most likely position of the QTL in the family used in the present study, it will be necessary to genotype all individuals from the family.

Evidence suggests the presence of a QTL for retail product yield and fat yield on chromosome 26. Stone et al. (1999) suggested the presence of a quantitative trait locus for retail product and fat yield at the centromeric end of this chromosome. As previously mentioned, Stone et al. (1999) used 185 offspring from a total of 547 offspring obtained from a crossbred Brahman and Hereford sire. When the entire family was genotyped, the QTL for these two traits on the family from this sire dropped below suggestive level (E. Casas, unpublished data). Evidence indicates that the most likely location of the QTL is between cM 15 and 41, whereas the QTL detected by Stone et al. (1999) is located between cM 5 and 6. It is unlikely that the QTL is the same in both studies.

The difference of the phenotypic effects of inheriting the Brahman allele and the Angus were estimated, but the magnitude is likely overestimated. Darvasi and Soller (1992) indicate that the observed differences in quantitative value associated with alternative marker genotypes in the selected population are greater than the actual gene effect at the quantitative trait locus when the entire population is considered. According to Darvasi and Soller (1992), the QTL effects for retail product yield and fat yield could be adjusted because these are the traits in which selective genotyping was based. However, the adjustment of overestimated effects in correlated traits is ambiguous, given that their adjustment would be weighed upon the genetic correlation of the trait with the traits that were used in selective genotyping. Unbiased estimates of the effects of the QTL can be obtained when all individuals from the family are genotyped and their information analysed.

\section{Acknowledgements}

Authors would like to thank Patty Beska, Kathy Mihm, Sandra Nejezchleb and Pat Tammen for technical support, and to Janice Watts for secretarial support.

\section{References}

Casas E., Shackelford S.D., Keele J.W., Stone R.T., Kappes S.M. \& Koohmaraie M. (2000) Quantitative trait loci affecting growth and carcass composition of cattle segregating alternate forms of myostatin. Journal of Animal Science 78, 560-9.

Casas E., Stone R.T., Keele J.W., Shackelford S.D., Kappes S.M. \& Koohmaraie M. (2001) A comprehensive search for QTL affecting growth and carcass composition of cattle segregating alternative forms of the myostatin gene. Journal of Animal Science 79, 854-60. 
Casas E., Shackelford S.D., Keele J.W., Koohmaraie M., Smith T.P.L. \& Stone R.T. (2003) Detection of quantitative trait loci for growth and carcass composition in cattle. Journal of Animal Science 81, 2976-83.

Darvasi A. \& Soller M. (1992) Selective genotyping for determination of linkage between a marker locus and a quantitative trait locus. Theoretical and Applied Genetics 85, 353-9.

Davis G.P., Hetzel D.J.S., Corbet N.J., Scacheri S., Lowden S., Renaud J., Mayne C., Stevenson R., Moore S.S. \& Byrne K. (1998) The mapping of QTL for birth weight in a tropical beef herd. 6th World Congress on Genetics Applied to Livestock Production 26, 441-4.

Haley C.S., Knott S.A. \& Elsen J.M. (1994) Mapping QTL in crosses between outbred lines using least squares. Genetics 136, 1195207.

Kappes S.M., Keele J.W., Stone R.T., McGraw R.A., Sonstegard T.S., Smith T.P.L. Lopez-Corrales N. \& Beattie C.W. (1997) A secondgeneration linkage map of the bovine genome. Genome Research 7, 235-49.

Keele J.W., Shackelford S.D., Kappes S.M., Koohmaraie M. \& Stone R.T. (1999) A region on bovine chromosome 15 influences beef longissimus tenderness in steers. Journal of Animal Science 77, 1364-71.

Kim J.-J., Farnir F., Savell J. \& Taylor J.F. (2003) Detection of quantitative trait loci for growth and beef carcass fatness traits in a cross between Bos taurus (Angus) and Bos indicus (Brahman) cattle. Journal of Animal Science 81, 1933-42.

Lander E.S. \& Botstein D. (1989) Mapping Medelian factors underlying quantitative traits using RFLP linkage maps. Genetics 99, 541-553.

Lander E.S. \& Kruglyak L. (1995) Genetic dissection of complex traits: guidelines for interpreting and reporting linkage results. Nature Genetics 11, 241-7.

MacNeil M.D. \& Grosz M.D. (2002) Genome-wide scans for QTL affecting carcass traits in Hereford X composite double backcross populations. Journal of Animal Science 80, 2316-24.

Miller S.A., Dykes D.D. \& Polesky H.F. 1988. A simple salting out procedure for extracting DNA from human nucleated cells. Nucleic Acids Research 16, 1215.

Ott J. (1992) Methods of linkage analysis. In: Analysis of Human Genetic Linkage. Revised edition. The Johns Hopkins University Press, Baltimore, M.D. pp. 65-68.

Shackelford S.D., Cundiff L.V., Gregory K.E. \& Koohmaraie M. (1995) Predicting beef carcass cutability. Journal of Animal Science 73, 406-13.

Stone R.T., Keele J.W., Shackelford S.D., Kappes S.M. \& Koohmaraie M. (1999) A primary screen of the bovine genome for QTL affecting carcass and growth traits. Journal of Animal Science 77, 1379-84. 